\title{
Article \\ Electromagnetic Interference Shielding Anisotropy of Unidirectional CFRP Composites
}

\author{
Jun Hong * and Ping $\mathrm{Xu}$
}

Citation: Hong, J.; Xu, P.

Electromagnetic Interference

Shielding Anisotropy of

Unidirectional CFRP Composites.

Materials 2021, 14, 1907.

https://doi.org/10.3390/

ma14081907

Academic Editor: Michal Sedlačík

Received: 4 March 2021

Accepted: 8 April 2021

Published: 11 April 2021

Publisher's Note: MDPI stays neutral with regard to jurisdictional claims in published maps and institutional affiliations.

Copyright: (c) 2021 by the authors. Licensee MDPI, Basel, Switzerland. This article is an open access article distributed under the terms and conditions of the Creative Commons Attribution (CC BY) license (https:// creativecommons.org/licenses/by/ $4.0 /)$.
Interdisciplinary Graduate School of Science and Technology, Shinshu University, Ueda 386-8567, Japan; 19hs110e@shinshu-u.ac.jp

* Correspondence: red1104@live.cn
Abstract: Carbon fiber-reinforced polymer (CFRP) composites have excellent mechanical properties and electromagnetic interference (EMI) shielding performance. Recently, their EMI shielding performance has also attracted great attention in many industrial fields to resolve electromagnetic pollution. The present paper mainly investigated the EMI shielding anisotropy of CFRP materials using a specified set-up of free-space measurement. The electrical conductivity of unidirectional CFRP composites was identified to vary with the fiber orientation angles, and the formula was proposed to predict the results consistent with the experimental. The obvious EMI shielding anisotropy of unidirectional CFRP composites was clarified by free-space measurement. The theoretical formula can predict the EMI shielding value at different carbon fiber orientation angles, and the predicted results were highly consistent with the experimental results. A comparison of the free-space measurement and the coaxial transmission line method was also conducted, which indicated that special attention should be paid to the influence of the anisotropy of CFRP composites on the shielding results. With those results, the mechanism of EMI shielding anisotropy of CFRP composites is clarified, which will provide an effective design of EMI shielding products with a designable shielding direction and frequency.

Keywords: unidirectional CFRP; EMI shielding; anisotropy; free-space measurement

\section{Introduction}

Recently, with the rapid development in communication and electronic devices, electromagnetic (EM) pollution has become a serious concern that can lead to electromagnetic compatibility (EMC) issues in electronic equipment and the resulting EM radiation of specific frequencies could be harmful to human health [1-5]. This is especially true as the market for $5 \mathrm{G}$ technologies and autonomous vehicles are growing rapidly around the world [6,7]. EM radiation usually causes electromagnetic interference (EMI) with other electronics, which can lead to electronic device malfunction [8]. Hence, research focused on effectively solving and avoiding EM pollution has attracted considerable attention.

Nowadays, shielding materials play a key role in protecting electronic equipment from EMI and prevent such radiation sources from emitting radio waves. EMI shielding refers to the absorption or reflection of EM waves with efficient shielding materials, which are composed of either conductive or magnetic-based materials $[9,10]$. In the past few decades, metal materials have been widely used as EMI shielding materials for excellent shielding performance, but they have disadvantages of low corrosion resistance, poor mechanical flexibility, etc. [11,12].

MXenes have been studied as EMI shielding materials due to their outstanding EMI shielding performance, low density and special metallic features $[13,14]$. The MXenes composites with different structures have been fabricated to improve its EMI shielding performance [15]. Besides, carbon materials have been investigated as alternatives to metal-based composites to provide great EMI shielding performance. Polymer composites reinforced with carbon-based fillers, such as carbon fibers, graphite, carbon nanotube 
(CNT), graphene and carbon black have been widely studied for use as shielding materials to provide great shielding abilities to EM waves [16-22]. Conventional carbon fiber reinforced polymer (CFRP) composites show not only good shielding properties, but also achieve excellent mechanical performance, which can expand their applications in the aeronautic industry [23-25]. Other research works [26,27] also observed excellent shielding performance of short carbon fiber reinforced composites, but its mechanical properties and EMI shielding performance were inferior to continuous carbon fiber composite materials $[28,29]$. Besides, the EMI shielding performance of CFRP could also be improved by being coated with conductive paints filled with metallic particles or nanowires [30], but it still meets the challenge of poor dispersion of conductive fillers and poor wear. In recent years, intrinsically conducting polymers (ICPs) have also been used as fillers for EMI shielding [31-33], but their poor mechanical and thermal properties limit their practical applications [34].

The shielding materials should obtain excellent EMI shielding performance in the specified frequency range to meet different practical applications. Many studies have achieved the purpose of improving the EMI shielding performance of composite materials in a specific frequency band by controlling the filler's size. Jana et al. [35] found that the composite with high carbon fiber aspect ratio $(\mathrm{L} / \mathrm{D}=100)$ shows higher shielding effectiveness in the frequency range of 8-12 GHz (X-band). Zhao et al. [36] reported that shielding performance of CFRP was enhanced with the decrease in the array spacing and the increased number of layers in the frequency range of $30-750 \mathrm{MHz}$, but the number of layers exhibited little effect on the EMI shielding of CFRP at the frequency range of $750 \mathrm{MHz}-$ $1.5 \mathrm{GHz}$. The shielding property of carbon nano-fiber-based composites is also improved in the X-band by increasing the magnetic particle size introduced into the matrix [37]. As above all, shielding materials with various filler sizes and structures exhibit different shielding performances in various frequency bands. In this study, EMI shielding anisotropy of unidirectional CFRP composites was investigated in the frequency range of 5-15 GHz, which is often used in wireless computer networks, radar and satellite communication.

Continuous carbon fiber-reinforced polymer composites have been widely used as structural materials for lightweight structures and EMI shielding applications. However, most researches have focused on the improvement of EMI shielding performance by adjusting the fiber lay-up arrangement or structure [36,38]. Wen et al. [39] reported that the EMI shielding effectiveness (SE) of PVB/Ni-Gr/SCF films exhibited different performances along and perpendicular to the casting direction, where the short carbon fiber direction was changed. Hong et al. [40] indicated that the orientation of fillers could play an important role in determining EMI SE in the polymer-based composites with magnetically responsive aligned $\mathrm{Fe}_{3} \mathrm{O}_{4}$ decorated reduced graphene oxide. The previous works $[39,41]$ revealed that the distribution state of fillers plays an important role in the shielding performance of composites, but the shielding anisotropy was not analyzed further. The carbon fiber orientation has a significant influence on the EMI shielding performance of CFRP composites. However, the EMI shielding anisotropy of unidirectional CFRP, especially its shielding anisotropy mechanisms and SE prediction, has not been systematically investigated and reported. This paper aims to provide a theoretical analysis of the shielding anisotropy of CFRP composites and propose formulas to predict electrical conductivity and EMI SE of CFRP at different orientation angles.

This study mainly discussed the EMI shielding anisotropy of unidirectional CFRP composites. A specially designed free-space measurement was set up in a one direction vibration of the incident EM wave, which can measure the EMI shielding performance in any specified direction. The EMI shielding anisotropy of unidirectional CFRP composites was discussed, and the theoretical formula was used to predict the EMI SE of CFRP at various carbon fiber orientations. The shielding results of the free-space measurement and coaxial transmission line method were compared, and the influence of the EMI shielding anisotropy on the test results with different measurements was discussed. 


\section{Materials and Methods}

\subsection{Fabrication of Unidirectional CFRP Composites}

The XN80 carbon fiber-based unidirectional prepregs were supplied by Japan Graphite Fiber Co., Ltd. The carbon fiber areal density was $125 \mathrm{~g} / \mathrm{m}^{2}$, and the thickness of an individual prepreg was about $0.165 \mathrm{~mm}$. The XN80 carbon fiber had an excellent tensile strength (3430 MPa), tensile modulus (780 GPa), electrical conductivity $\left(5 \times 10^{-4} \mathrm{ohm} \mathrm{cm}\right)$, and the fiber diameter was about $10 \mu \mathrm{m}$. A four-layered unidirectional CFRP composite was made of four single prepregs arranged in the same fiber direction. The CFRP composites were cured by the hot press machine at $135^{\circ} \mathrm{C}$ and $2 \mathrm{MPa}$ for $1.5 \mathrm{~h}$. The CFRP composite was a square with a side length of $25 \mathrm{~cm}$ and a thickness of $0.55 \mathrm{~mm}$.

\subsection{Electrical Conductivity of CFRP Composites}

The electrical conductivity of the unidirectional CFRP composites was tested by the fourprobe method [28]. All specimens had a uniform dimension of $80 \mathrm{~mm} \times 10 \mathrm{~mm} \times 0.55 \mathrm{~mm}$, and a silver paint was used to ensure good contact between the electrodes and specimens during testing. Four electrical contacts were symmetrically positioned relative to the center of the specimen, and the distance between the adjacent electrical contact was about $20 \mathrm{~mm}$. Each electrical contact with silver paint was $2 \mathrm{~mm}$ wide. A current of $0.1 \mathrm{~mA}$ was provided by the DC power supply device (Takasago EX-375L2, Takasago Ltd., Kanagawa, Japan) at the outer electrical contacts, and the digital electrometer (Advantest R8240, Advantest Corporation, Tokyo, Japan) was used to measure the voltage at the inner contacts. Each test was carried out 5 times. Since the carbon fibers were arranged in the same direction in the unidirectional CFRPs, their ability to transfer electrons was different at various fiber orientations. The electrical conductivity of the specimens was measured at $0^{\circ}, 15^{\circ} 30^{\circ}, 45^{\circ}$, $60^{\circ}, 75^{\circ}$, and $90^{\circ}$. Where the $0^{\circ}$ direction refers to the fiber direction, and $90^{\circ}$ refers to the direction perpendicular to the carbon fiber.

\subsection{EMI Shielding Measurement}

The EMI shielding performance of the CFRP composites was test by the free-space measurement method. The specially designed free-space measurement system (KEYCOM RTS03, KEYCOM Corporation, Tokyo, Japan) consists of two antennas, two lens and a sample stage, as shown in Figure 1. The electric field of the incident EM waves was linearly polarized. Figure 2 shows the distribution of the electric field inside the coaxial tube and the specimen dimension used for coaxial transmission line measurement (KEYCOM S-GPC7, KEYCOM Corporation, Tokyo, Japan). The value of the scattering parameters ( $S_{21}$ or $S_{12}$ ) of the CFRP materials were tested by the vector network analyzer (Anritsu 37247D, Anritsu Corporation, Kanagawa, Japan). The attenuation of the EM wave was defined as the $S E$, which can be calculated by the following equations:

$$
\begin{gathered}
S E=10 \log \left(\frac{P_{T}}{P_{I}}\right) \\
S E=-10 \log \left(\left|S_{21}\right|^{2}\right)=-10 \log \left(\left|S_{12}\right|^{2}\right)
\end{gathered}
$$

where $P_{T}$ is the transmitted power, $P_{I}$ is the incident power, and the $S_{12}\left(S_{21}\right)$ parameters refer to the transmission coefficients. 


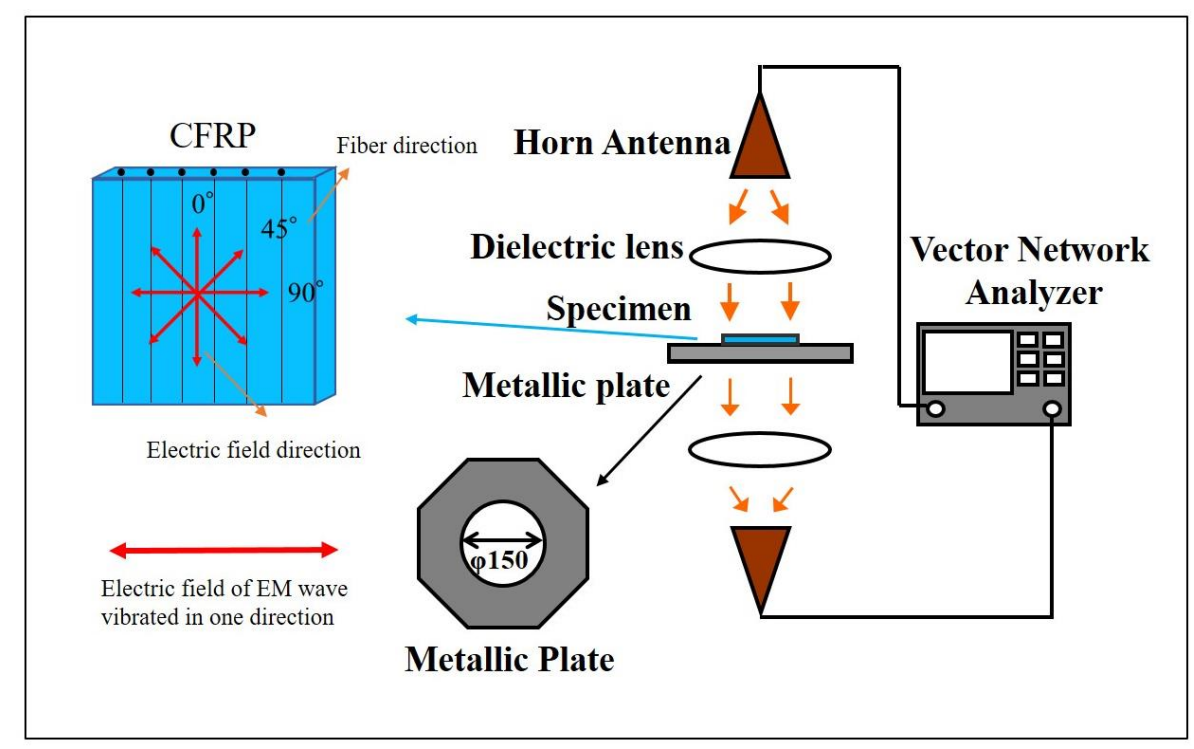

Figure 1. Schematic of free-space set-up for electromagnetic interference (EMI) shielding measurement. CFRP: carbon fiber-reinforced polymer.
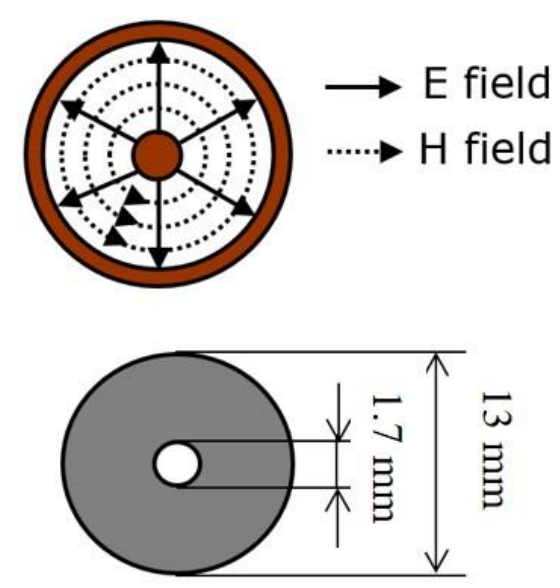

specimen

Figure 2. Distribution of the electric field inside the coaxial tube and the specimen dimension used for coaxial transmission line measurement.

\section{Results}

\subsection{Electrical Conductivity of Unidirectional CFRP Composite}

Figure 3 shows the electrical conductivity of CFRP at the different fiber orientations of $0^{\circ}, 15^{\circ}, 30^{\circ}, 45^{\circ}, 60^{\circ}, 75^{\circ}$ and $90^{\circ}$ (red dots). The conductivity of CFRP decreased as the fiber orientation angle increased from $0^{\circ}$ to $90^{\circ}$. An anisotropic CFRP composite was described as that all the fibers are highly aligned and parallel to each other in the composite. However, the fibers are not entirely straight and have a wave shape in the composite, consequently creating many contact points between adjacent fibers. This causes the composite to have specific electrical conductivity in the transverse direction of the fiber, although it is extremely lower compared with that in the fiber direction. As a consequence, the unidirectional CFRP composite shows the highest and lowest conductivity values in the fiber direction and transverse direction, respectively. 


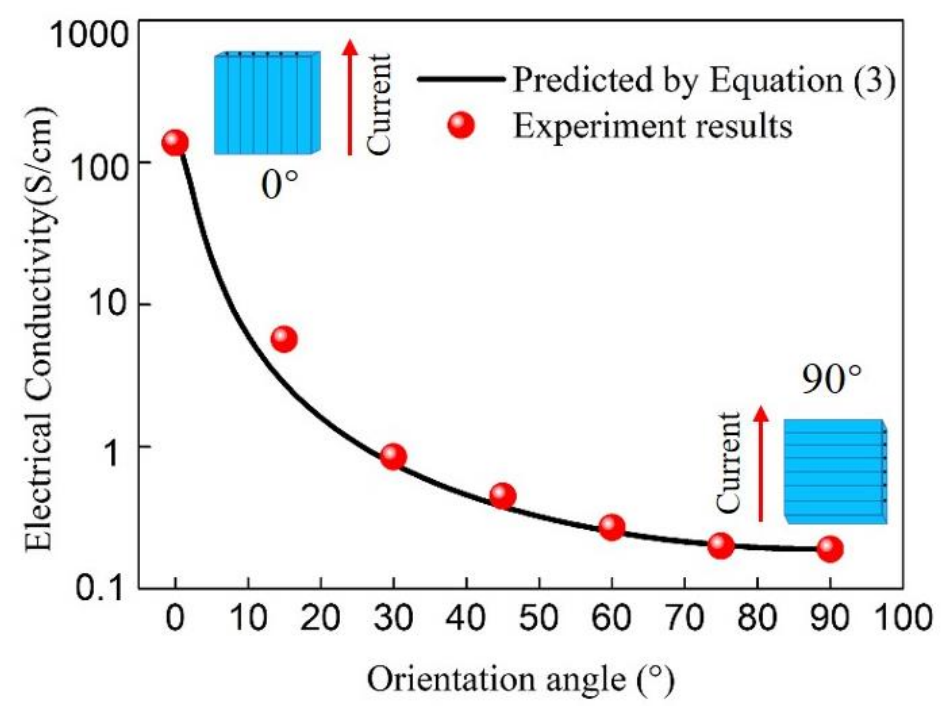

Figure 3. Electrical conductivity of the CFRP at different carbon fiber orientation angles.

The decreasing tendency of conductivity was not linear of CFRP, which decreased as the fiber orientation angle increased from $0^{\circ}$ to $90^{\circ}$. The conductivity decreased sharply from $0^{\circ}$ to around $30^{\circ}$, and the decreasing trend became gradual when exceeding $30^{\circ}$. Since the conductivity of CFRP presents a cosine change trend, the conductivity at different angles can be calculated and predicted by the formula derived below:

$$
\sigma_{\theta}=\frac{1}{A \cos ^{2}(\theta+\pi)+B} \quad 0 \leq \theta \leq \frac{\pi}{2}
$$

where $\sigma_{\theta}$ is the electrical conductivity of CFRP at $\theta$ degree, $A=1 / \sigma_{0}-1 / \sigma_{90}, B=1 / \sigma_{90}, \sigma_{0}$ and $\sigma_{90}$ are the electrical conductivity of CFRP at the testing angle of $0^{\circ}$ and $90^{\circ}$, respectively.

The curve in Figure 3 shows the predicted electrical conductivity of unidirectional CFRP as a function of the carbon fiber orientation angle from $0^{\circ}$ to $90^{\circ}$. It can be seen from Figure 3 that the calculated results are in good agreement with the experimental results, indicating that the proposed formula can predict the electrical conductivity of unidirectional CFRP at any angle just through the conductivity values at $0^{\circ}$ and $90^{\circ}$ directions.

\subsection{Skin Depth of Unidirectional CFRP Composite}

When the EM wave is incident on the surface of the material, the displacement current of the wave is coupled to it and generates the magnetic field at a right angle, which can create a back electromotive force to cause a force named the "skin effect" [42]. As the propagation depth increase, more EM waves are attenuated. When the strength of the EM wave is reduced to 1/e of the incident strength, the distance is known as the skin depth [43], and can be calculated by the following equation [44]:

$$
\delta=1 / \sqrt{\pi \mu f \sigma}
$$

where $\delta$ is the skin depth, $f$ is the frequency, and $\sigma$ is the electrical conductivity of the material. The magnetic permeability $\mu=\mu_{0} \mu_{r}$, where the magnetic permeability of vacuum $\left(\mu_{0}\right)$ is $4 \pi \times 10^{-7} \mathrm{H} / \mathrm{m}$, and the relative magnetic permeability $\left(\mu_{r}\right)$ of CFRP is about $1[28,45]$.

Figure 4 shows the skin depth of unidirectional CFRP as a function of carbon fiber orientation angles at different frequencies. The skin depth of the composite decreased with an increase in the orientation angle. This is mainly due to the decrease in conductivity as the carbon fiber orientation angle increases, as shown in the conductivity results in Figure 3. The skin depth also decreases as the frequency increases. At a frequency of $15 \mathrm{GHz}$, the 
CFRP had the lowest skin depth value of $0.035 \mathrm{~mm}$ in the $0^{\circ}$ direction, which refers to the fiber direction. At $5 \mathrm{GHz}$, CFRP obtained a maximum value of $1.633 \mathrm{~mm}$ in $90^{\circ}$ direction.

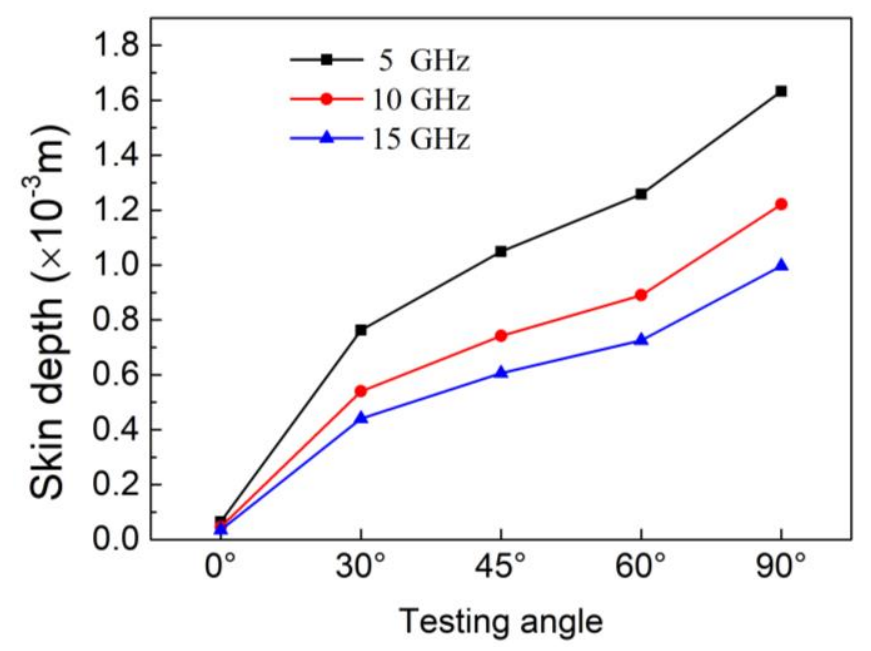

Figure 4. Skin depth of CFRP as a function of testing angles.

The thickness of the fabricated unidirectional CFRP was about $0.55 \mathrm{~mm}$. According to the definition of skin depth, when the frequency is $15 \mathrm{GHz}$, and the electric field of the EM wave is consistent with the fiber direction, the electric field intensity would be less than 1/e of the incident electric field intensity when the EM waves penetrate through the CFRP composite. At $5 \mathrm{GHz}$, when the electric field is perpendicular to the fiber direction, the electric field intensity would be greater than 1 /e of the incident electric field intensity when the EM waves pass through the CFRP. Consequently, the skin depth of materials plays a key role in the attenuation of EM waves, and due to the dependence of the skin depth on the carbon fiber orientation angle, the EMI shielding performance of CFRP would be different at various carbon fiber directions.

\subsection{EMI Shielding Theory of CFRP Composite}

According to the circuit theory [42] for calculating the EM wave attenuation by shielding, the displacement current in the wave would be coupled to the CFRP when the EM wave encounters the CFRP composite, as shown in Figure 5. Then, the surface current density onto the CFRP will generate a magnetic field $(\mathrm{H})$ perpendicular to it, and the magnetic field would create an opposite electromotive force, which can attenuate the current to penetrate the CFRP. This phenomenon leads to the attenuation of EM waves. The shielding attenuation $S(d B)$ for the electric field $(E)$ can be obtained as follows:

$$
S(d B)=20 \log \frac{E_{I}}{E_{T}}=20 \log \frac{J_{I} Z_{W}}{J_{T} Z_{C}}
$$

where $E_{I}$ and $E_{\mathrm{T}}$ are the electric field at the incident side and transmitted side, respectively; $J_{I}$ is the surface current density at the incident side of the CFRP, and the current value at the transmitted side $J_{T}$ is expressed as:

$$
J_{T}=J_{I} e^{-d / \delta}
$$

where $d$ is the thickness of CFRP, and $\delta$ is the skin depth.

$Z_{W}$ and $Z_{C}$ are the impedance of the incident wave and CFRP composites, respectively, which is equal to:

$$
Z_{W}=-\frac{j 377 \lambda}{2 \pi L}\left(L<\frac{\lambda}{2 \pi}\right)=377\left(L \geq \frac{\lambda}{2 \pi}\right)
$$




$$
\mathrm{Z}_{\mathrm{C}}=\frac{1+j}{\sigma \delta\left(1-e^{-d / \delta}\right)}
$$

where $\sigma$ is the electrical conductivity of the CFRP composite. Then, the shielding attenuation $S E(d B)$ of the CFRP composite can be expressed as:

$$
S E(d B)=20 \log \frac{Z_{W}}{e^{-d / \delta} \cdot Z_{C}} .
$$

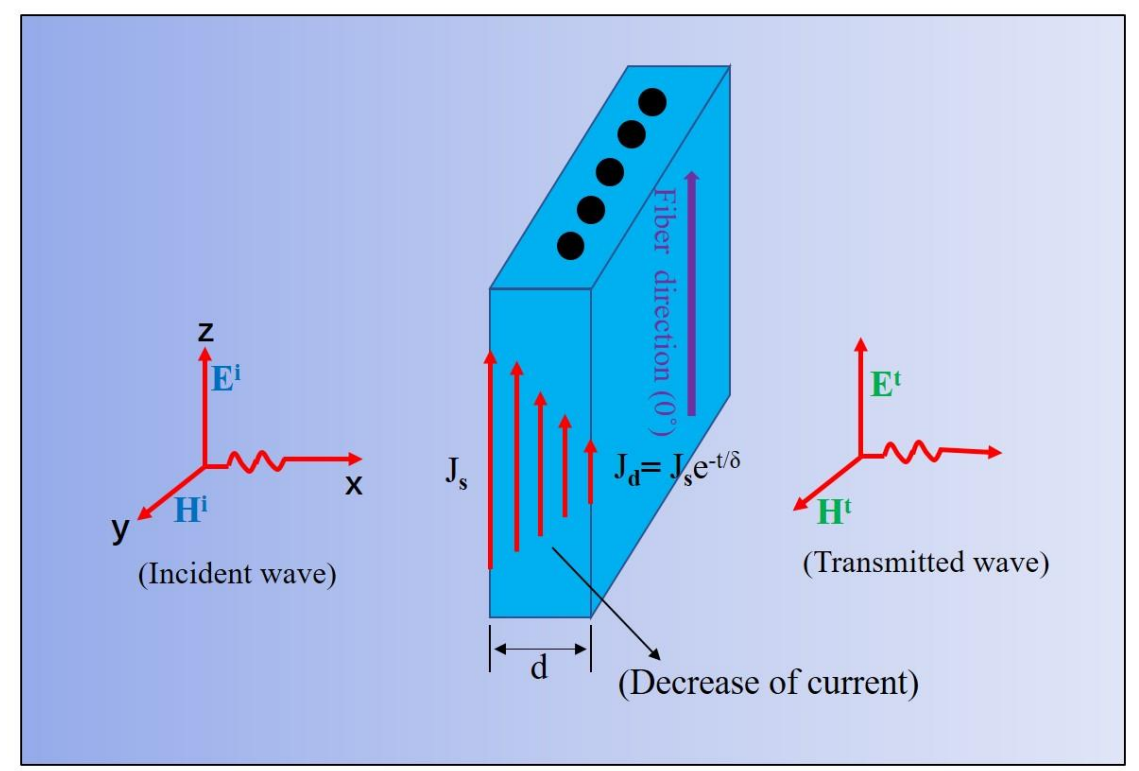

Figure 5. Schematic of EMI shielding mechanism of unidirectional CFRP.

According to Equation (9), the thickness and skin depth of the material plays a decisive role in the EM shielding performance. The formula's applicability in the frequency range of $5-15 \mathrm{GHz}$ was verified by taking the test angles of $45^{\circ}$ and $90^{\circ}$ as examples. The skin depth, electrical conductivity, and related parameters were substituted into Equation (9). The comparison between the calculated prediction and the experimental results by the free space measurement is shown in Figure 6. It was observed that the experimental and predicted result were in good agreement. The maximum difference at fiber orientation of $45^{\circ}$ is only about $1.9 \mathrm{~dB}$. It can be concluded that Equation (9) can be applied to predict the EMI SE of unidirectional CFRP at the frequency range of 5 to $15 \mathrm{GHz}$.

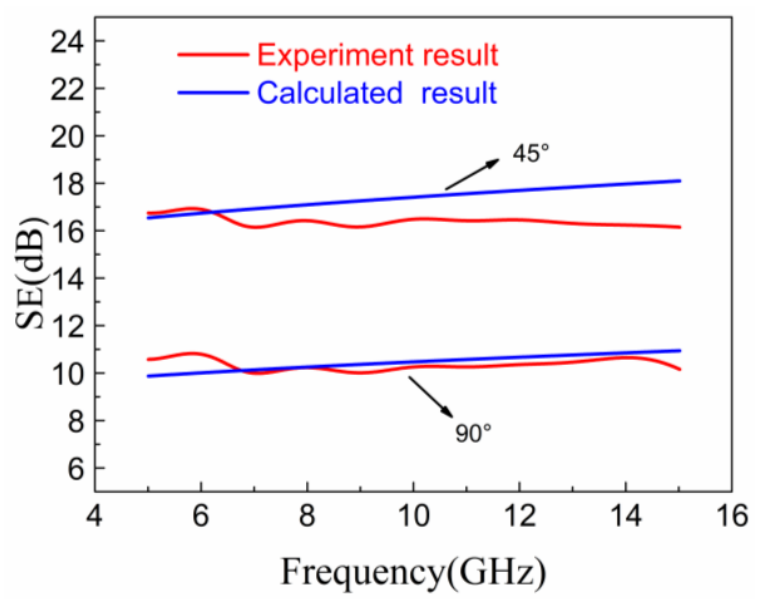

Figure 6. Comparison of experimental value and formula calculation value of EMI SE. 
By combining Equations (3) and (9), the EMI SE of unidirectional CFRP could be predicted at any carbon fiber orientation angles. Figure 7 shows that the predicted results are highly consistent with the experimental results in the various fiber directions at $10 \mathrm{GHz}$. When only using Equation (9) to calculate the shielding performance of CFRP at different orientation angles, it is necessary to test the material's EM parameters (skin depth, electrical conductivity, etc.) in each direction. Here, Equations (3) and (9) are used in combination, and it is only necessary to calculate or measure the electromagnetic parameters of CFRP in the $0^{\circ}$ and $90^{\circ}$ directions and substituting the results into the Equation (9) to obtain the EMI SE at any carbon fiber orientation angles. The predicted results were highly in good agreement with the experimental values. There was a difference between the experimental and calculated results in the fiber direction $\left(0^{\circ}\right)$. That might be due to the device limitation; that is, the EMI SE of the CFRP materials might have exceeded the measuring range of the device in the fiber direction.

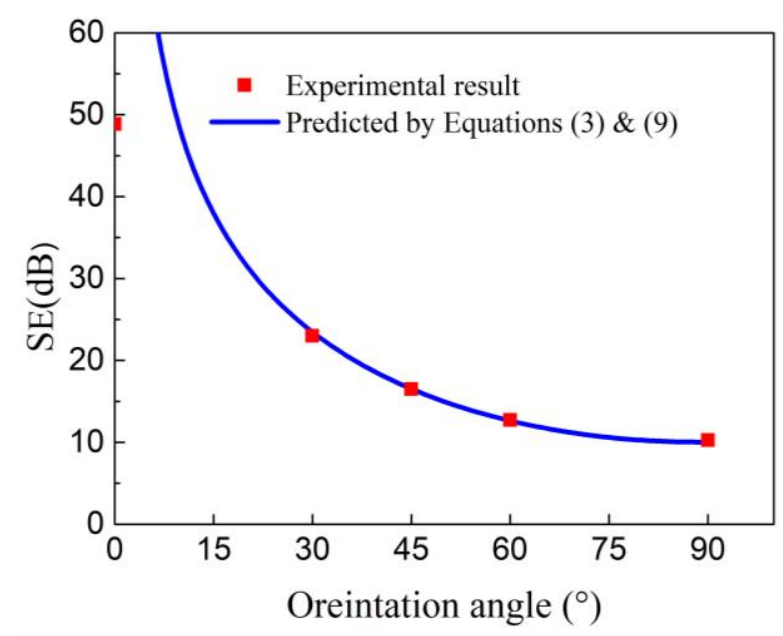

Figure 7. EMI SE of CFRP for experimental and predicted results at the frequency of $10 \mathrm{GHz}$.

\subsection{Comparison of Coaxial Transmission Line Method and Free-Space Measurement}

To further understand the relationship between the EMI shielding performance and carbon fiber orientation, the shielding result obtained by the transmission line method was compared to that by free-space measurement. The EMI shielding performance of unidirectional CFRP with a carbon fiber orientation angle of $0,30,45,60$, and $90^{\circ}$ at the frequencies from 5 to $15 \mathrm{GHz}$ are shown in Figure 8. CFRP showed an excellent electromagnetic shielding value when the carbon fiber orientation angle is $0^{\circ}$, where the electric field polarization direction of EM waves is parallel to the fiber direction. The SE of CFRP decreased as the fiber orientation angle increased due to the decrease in electrical conductivity. When the orientation angle was $90^{\circ}$, the electric field polarization direction was perpendicular to the carbon fiber, and the CFRP obtained the lowest electrical conductivity in this orientation angle. Thus, CFRP showed the lowest SE value of about $10 \mathrm{~dB}$.

The red curve in Figure 8 represents the EMI shielding result measured by using the coaxial transmission line method. The SE value obtained by this method was about $19 \mathrm{~dB}$. This is due to the fact that the electric field of EM waves was quasi-radially distributed inside the coaxial tube (Figure 2), which has been discussed in our previous work [46]. When the coaxial transmission line method was adopted to evaluate the EMI shielding performance of unidirectional CFRP, the EMI shielding result did not change if the position of the composite material was rotated along the inner conductor. However, under the free-space measurement system, the EMI shielding performance greatly depended on the test angle. Unidirectional CFRP exhibits remarkable EMI shielding anisotropy. This characteristic of the one-side composite material can be used for the bias material of EM wave radiation, meaning that the EM waves polarized in a specific direction can be selectively shielded by adjusting the angle of the CFRP composites. 


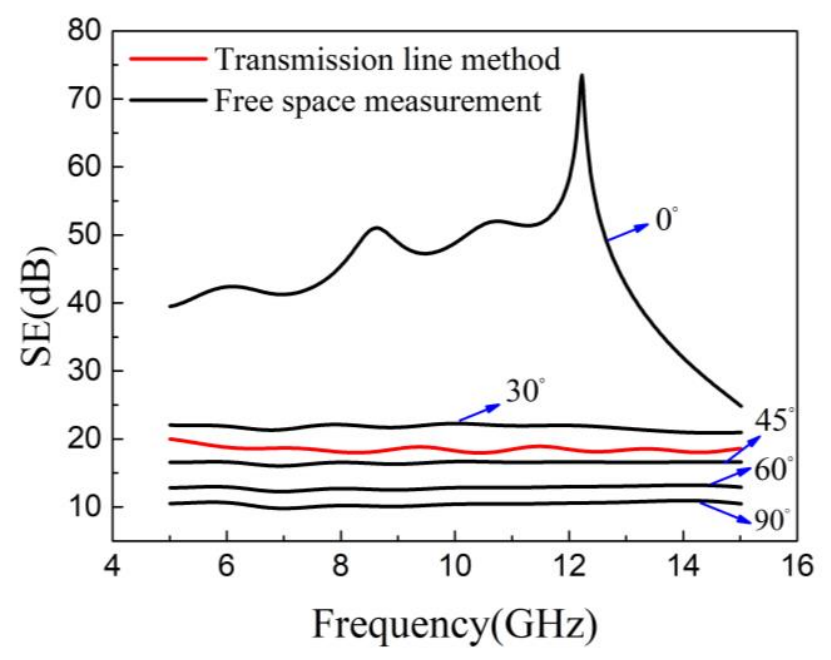

Figure 8. EMI SE of CFRP by the transmission line method and free-space method.

The results show that when different test methods are used to evaluate the shielding performance of unidirectional CFRP composites, the results will differ. Therefore, when assessing anisotropic materials, especially materials prepared by CFRP prepregs, special attention should be paid to the influence of electromagnetic shielding anisotropy.

\section{Conclusions}

Carbon fiber-reinforced composite materials occupy a critical position in many structural material applications, and their EM shielding performance has also attracted great attention. This study mainly investigated the EMI shielding anisotropy of CFRP materials.

The electrical conductivity of unidirectional CFRP composites varies due to the fiber orientation angles, and the calculated results by the formulas proposed in this study were highly consistent with the experiment values. It was found that the skin depth of unidirectional CFRP was different at various orientation angles and frequencies. At a frequency of $15 \mathrm{GHz}$, the CFRP exhibited the lowest skin depth value of $0.035 \mathrm{~mm}$ in the $0^{\circ}$ direction. All the characteristics mentioned above are key issues leading to the EMI shielding anisotropy of CFRP composites. The obvious EMI shielding anisotropy of unidirectional CFRP composites is clarified by the experimental results using the specified set-up of free-space measurement. The shielding results predicted by the theoretical formula are highly consistent with the experimental results. The maximum difference between the predicted and experimental values at a fiber orientation of $45^{\circ}$ is only about $1.9 \mathrm{~dB}$.

A comparison of the free-space measurement and the coaxial transmission line method was also conducted, and the influence of electric anisotropy on the test results was further discussed. The SE values obtained by the coaxial transmission line method was much lower than that obtained by the free-space measurement tested in the fiber direction, which indicated that special attention should be paid to the influence of the anisotropy of CFRP composites on the shielding results when evaluated by various measurements. With these results, the mechanism of EMI shielding anisotropy of CFRP composites is clarified, which will provide an effective design of EMI shielding products with a designable shielding direction and frequency.

Author Contributions: Conceptualization, J.H.; methodology, J.H. and P.X.; validation, J.H.; formal analysis, J.H.; investigation, J.H. and P.X.; resources, J.H.; data curation, J.H. and P.X.; writingoriginal draft preparation, J.H.; writing—review and editing, J.H. and P.X.; supervision, J.H.; project administration, J.H. All authors have read and agreed to the published version of the manuscript.

Funding: This research received no external funding.

Institutional Review Board Statement: Not applicable. 
Informed Consent Statement: Not applicable.

Acknowledgments: This work was supported by the Japan Society for the Promotion of Science (JSPS KAKENHI 26420721) and National Science Foundation of China (No. 52073259).

Conflicts of Interest: The authors declare no conflict of interest.

\section{References}

1. Song, W.-L.; Guan, X.-T.; Fan, L.-Z.; Cao, W.-Q.; Wang, C.-Y.; Zhao, Q.-L.; Cao, M.-S. Magnetic and conductive graphene papers toward thin layers of effective electromagnetic shielding. J. Mater. Chem. A 2015, 3, 2097-2107. [CrossRef]

2. Yu, Z.; Dai, T.; Yuan, S.; Zou, H.; Liu, P. Electromagnetic Interference Shielding Performance of Anisotropic Polyimide/Graphene Composite Aerogels. ACS Appl. Mater. Interfaces 2020, 12, 30990-31001. [CrossRef] [PubMed]

3. Ma, J.; Wang, K.; Zhan, M. A comparative study of structure and electromagnetic interference shielding performance for silver nanostructures hybrid polyimide foams. RSC Adv. 2015, 5, 65283-65296. [CrossRef]

4. Batrakov, K.; Kuzhir, P.; Maksimenko, S.; Paddubskaya, A.; Voronovich, S.; Lambin, P.; Kaplas, T.; Svirko, Y. Flexible transparent graphene/polymer multilayers for efficient electromagnetic field absorption. Sci. Rep. 2014, 4, 7191. [CrossRef]

5. Jang, J.M.; Lee, H.S.; Singh, J.K. Electromagnetic Shielding Performance of Different Metallic Coatings Deposited by Arc Thermal Spray Process. Materials 2020, 13, 5776. [CrossRef]

6. Joo, K.; Lee, K.J.; Jun Sung, H.; Lee, S.J.; Young Jeong, S.; Park, H.H.; Kim, Y.-H. Evaluation of package-level EMI shielding using conformally coated conductive and magnetic materials in low and high frequency ranges. In Proceedings of the 2020 IEEE 70th Electronic Components and Technology Conference (ECTC), Orlando, FL, USA, 3-30 June 2020.

7. Tsai, M.; Chiu, R.; He, E.; Chen, J.Y.; Chu, F.; Tsai, J.; Wang, Y.-P.; Jian, S.; Chen, S. Innovative EMI Shielding Solutions on Advanced SiP Module for 5G Application. In Proceedings of the 2019 21st Electronics Packaging Technology Conference, Singapore, 4-6 December 2019.

8. Chung, D.D.L. Materials for electromagnetic interference shielding. Mater. Chem. Phys. 2020, 255, 123587. [CrossRef]

9. Sankaran, S.; Deshmukh, K.; Ahamed, M.B.; Khadheer Pasha, S.K. Recent advances in electromagnetic interference shielding properties of metal and carbon filler reinforced flexible polymer composites: A review. Compos. Part A Appl. Sci. Manuf. 2018, 114, 49-71. [CrossRef]

10. Joshi, A.; Datar, S. Carbon nanostructure composite for electromagnetic interference shielding. Pramana 2015, 84, 1099-1116. [CrossRef]

11. Abbasi, H.; Antunes, M.; Velasco, J.I. Recent advances in carbon-based polymer nanocomposites for electromagnetic interference shielding. Prog. Mater. Sci. 2019, 103, 319-373. [CrossRef]

12. Ibrahim Lakin, I.; Abbas, Z.; Azis, R.S.; Abubakar Alhaji, I. Complex Permittivity and Electromagnetic Interference Shielding Effectiveness of OPEFB Fiber-Polylactic Acid Filled with Reduced Graphene Oxide. Materials 2020, 13, 4602. [CrossRef]

13. Wang, Z.; Cheng, Z.; Fang, C.; Hou, X.; Xie, L. Recent advances in MXenes composites for electromagnetic interference shielding and microwave absorption. Compos. Part A Appl. Sci. Manuf. 2020, 136, 105956. [CrossRef]

14. Li, X.; Yin, X.; Liang, S.; Li, M.; Cheng, L.; Zhang, L. 2D carbide MXene Ti2CTX as a novel high-performance electromagnetic interference shielding material. Carbon 2019, 146, 210-217. [CrossRef]

15. Iqbal, A.; Sambyal, P.; Koo, C.M. 2D MXenes for Electromagnetic Shielding: A Review. Adv. Funct. Mater. 2020, $30,2000883$. [CrossRef]

16. Panwar, V.; Park, J.-O.; Park, S.-H.; Kumar, S.; Mehra, R.M. Electrical, dielectric, and electromagnetic shielding properties of polypropylene-graphite composites. J. Appl. Polym. Sci. 2010, 115, 1306-1314. [CrossRef]

17. Mohan, R.R.; Varma, S.J.; Faisal, M.; Jayalekshmi, S. Polyaniline/graphene hybrid film as an effective broadband electromagnetic shield. RSC Adv. 2015, 5, 5917-5923. [CrossRef]

18. Wu, H.-Y.; Jia, L.-C.; Yan, D.-X.; Gao, J.-f.; Zhang, X.-P.; Ren, P.-G.; Li, Z.-M. Simultaneously improved electromagnetic interference shielding and mechanical performance of segregated carbon nanotube/polypropylene composite via solid phase molding. Compos. Sci. Technol. 2018, 156, 87-94. [CrossRef]

19. Hu, Y.; Li, D.; Wu, L.; Yang, J.; Jian, X.; Bin, Y. Carbon nanotube buckypaper and buckypaper/polypropylene composites for high shielding effectiveness and absorption-dominated shielding material. Compos. Sci. Technol. 2019, 181, 107699. [CrossRef]

20. Bagotia, N.; Choudhary, V.; Sharma, D.K. Synergistic effect of graphene/multiwalled carbon nanotube hybrid fillers on mechanical, electrical and EMI shielding properties of polycarbonate/ethylene methyl acrylate nanocomposites. Comp. Part B Eng. 2019, 159, 378-388. [CrossRef]

21. Wan, Y.-J.; Zhu, P.-L.; Yu, S.-H.; Sun, R.; Wong, C.-P.; Liao, W.-H. Graphene paper for exceptional EMI shielding performance using large-sized graphene oxide sheets and doping strategy. Carbon 2017, 122, 74-81. [CrossRef]

22. Zeranska-Chudek, K.; Siemion, A.; Palka, N.; Mdarhri, A.; Elaboudi, I.; Brosseau, C.; Zdrojek, M. Terahertz Shielding Properties of Carbon Black Based Polymer Nanocomposites. Materials 2021, 14, 835. [CrossRef]

23. Munalli, D.; Dimitrakis, G.; Chronopoulos, D.; Greedy, S.; Long, A. Electromagnetic shielding effectiveness of carbon fibre reinforced composites. Compos. Part B Eng. 2019, 173, 106906. [CrossRef]

24. Yang, S.; Lozano, K.; Lomeli, A.; Foltz, H.D.; Jones, R. Electromagnetic interference shielding effectiveness of carbon nanofiber/LCP composites. Compos. Part A Appl. Sci. 2005, 36, 691-697. [CrossRef] 
25. Chung, D.D.L. Carbon materials for structural self-sensing, electromagnetic shielding and thermal interfacing. Carbon 2012, 50, 3342-3353. [CrossRef]

26. Liang, J.-Z.; Yang, Q.-Q. Effects of carbon fiber content and size on electric conductive properties of reinforced high density polyethylene composites. Compos. Part B Eng. 2017, 114, 457-466. [CrossRef]

27. Chen, X.; Gu, Y.; Liang, J.; Bai, M.; Wang, S.; Li, M.; Zhang, Z. Enhanced microwave shielding effectiveness and suppressed reflection of chopped carbon fiber felt by electrostatic flocking of carbon fiber. Compos. Part A Appl. Sci. Manuf. 2020, 139, 106099. [CrossRef]

28. Chung, D.D.L.; Eddib, A.A. Effect of fiber lay-up configuration on the electromagnetic interference shielding effectiveness of continuous carbon fiber polymer-matrix composite. Carbon 2019, 141, 685-691. [CrossRef]

29. Luo, X.; Chung, D. Electromagnetic interference shielding using continuous carbon-fiber carbon matrix and polymer-matrix composites. Compos. Part B Eng. 1999, 30, 227-231. [CrossRef]

30. Dupenne, D.; Lonjon, A.; Dantras, E.; Pierré, T.; Lubineau, M.; Lacabanne, C. Carbon fiber reinforced polymer metallization via a conductive silver nanowires polyurethane coating for electromagnetic shielding. J. Appl. Polym. Sci. 2020, 138, 50146. [CrossRef]

31. Kumar, V.; Muflikhun, M.A.; Yokozeki, T. Improved environmental stability, electrical and EMI shielding properties of vaporgrown carbon fiber-filled polyaniline-based nanocomposite. Polym. Eng. Sci. 2018, 59, 956-963. [CrossRef]

32. Yin, G.; Wang, Y.; Wang, W.; Yu, D. Multilayer structured PANI/MXene/CF fabric for electromagnetic interference shielding constructed by layer-by-layer strategy. Colloids Surf. A Physicochem. Eng. Asp. 2020, 601, 125047. [CrossRef]

33. Yokozeki, T.; Goto, T.; Takahashi, T.; Qian, D.; Itou, S.; Hirano, Y.; Ishida, Y.; Ishibashi, M.; Ogasawara, T. Development and characterization of CFRP using a polyaniline-based conductive thermoset matrix. Compos. Sci. Technol. 2015, 117, $277-281$. [CrossRef]

34. Gupta, S.; Tai, N.-H. Carbon materials and their composites for electromagnetic interference shielding effectiveness in X-band Carbon 2019, 152, 159-187. [CrossRef]

35. Jana, P.B.; Mallick, A.K.; De, S.K. Effects of sample thickness and fiber aspect ratio on EMI shielding effectiveness of carbon fiber filled polychloroprene composites in the X-band frequency range. IEEE Trans. Electromagn. Compat. 1994, 34, 478-481. [CrossRef]

36. Zhao, X.; Fu, J.; Wang, H. The electromagnetic interference shielding performance of continuous carbon fiber composites with different arrangements. J. Ind. Text. 2015, 46, 45-58. [CrossRef]

37. Bayat, M.; Yang, H.; Ko, F. Effect of iron oxide nanoparticle size on electromagnetic properties of composite nanofibers. J. Compos. Mater. 2017, 52, 1723-1736. [CrossRef]

38. Hassan, A.M.; Douglas, J.F.; Garboczi, E.J. Computational modeling of the electromagnetic characteristics of carbon fiberreinforced polymer composites with different weave structures. Am. Inst. Phys. 2014, 1581, 1494-1499.

39. Wen, B.; Wang, X.; Zhang, Y. Ultrathin and anisotropic polyvinyl butyral/Ni-graphite/short-cut carbon fibre film with high electromagnetic shielding performance. Compos. Sci. Technol. 2019, 169, 127-134. [CrossRef]

40. Hong, S.Y.; Kim, Y.C.; Wang, M.; Nam, J.-D.; Suhr, J. Anisotropic electromagnetic interference shielding properties of polymerbased composites with magnetically-responsive aligned $\mathrm{Fe}_{3} \mathrm{O}_{4}$ decorated reduced graphene oxide. Eur. Polym. J. 2020, 127, 109595. [CrossRef]

41. Xu, Y.; Yang, Y.; Yan, D.; Duan, H.; Dong, C.; Zhao, G.; Liu, Y. Anisotropically conductive polypropylene/nickel coated glass fiber composite via magnetic field inducement. J. Mater. Sci. Mater. Electron. 2017, 28, 9126-9131. [CrossRef]

42. Kunke, G.M. Shielding of Electromagnetic Waves; Springer: Cham, Switzerland, 2020.

43. Liu, X.; Yin, X.; Kong, L.; Li, Q.; Liu, Y.; Duan, W.; Zhang, L.; Cheng, L. Fabrication and electromagnetic interference shielding effectiveness of carbon nanotube reinforced carbon fiber/pyrolytic carbon composites. Carbon 2014, 68, 501-510. [CrossRef]

44. Paul, C.R. Introduction to Electromagnetic Compatibility; John Wiley \& Sons, Inc.: Hoboken, NJ, USA, 2006.

45. Karbhari, V.M. Non-Destructive Evaluation (NDE) of Polymer Matrix Composites; Woodhead Publishing Limited: Sawston, UK, 2013.

46. Hong, J.; Xu, P.; Xia, H.; Xu, Z.; Ni, Q.-Q. Electromagnetic interference shielding anisotropy enhanced by CFRP laminated structures. Compos. Sci. Technol. 2021, 203, 108616. [CrossRef] 